\title{
Cyclooxygenase products and atherosclerosis
}

\author{
MacRae F. Linton, M.D ${ }^{*}, \#$ and Sergio Fazio, M.D., Ph.D ${ }^{\star}{ }^{\wedge}$ \\ ${ }^{*}$ Atherosclerosis Research Unit, Division of Cardiovascular Medicine, Department of Medicine, Vanderbilt \\ University Medical Center, Nashville, TN 37232, USA \\ ${ }^{\wedge}$ Department of Pathology, Vanderbilt University Medical Center, Nashville, TN 37232, USA \\ \#Department of Pharmacology, Vanderbilt University Medical Center, Nashville, TN 37232, USA
}

\begin{abstract}
Keywords
atherosclerosis; COX-2; COX-2 inhibitors; LDL-receptor deficient mice; macrophage; fetal liver cell transplantation
\end{abstract}

\section{Cyclooxygenase and Eicosanoid Production}

Eicosanoids play critical roles in inflammation and cardiovascular health and disease[1,2]. The rate-limiting enzyme in the biosynthesis of prostaglandins (PGs) is $\mathrm{PGH}_{2}$ synthase or cyclooxygenase (COX), which catalyses the first committed step in the biosynthesis of PGs by converting arachidonic acid (AA) to $\mathrm{PGH}_{2}[1,2]$. COX is a bifunctional enzyme in that it first oxidizes AA to $\mathrm{PGG}_{2}$ and then peroxidizes $\mathrm{PGG}_{2}$ to $\mathrm{PGH}_{2}$. $\mathrm{PGH}_{2}$ is metabolized further by specific synthases and isomerases into a variety of eicosanoids including $\mathrm{PGE}_{2}, \mathrm{PGD}_{2}$, $\mathrm{PGF}_{2 \alpha}$, prostacyclin $\left(\mathrm{PGI}_{2}\right.$ ), and thromboxane (TX) $\mathrm{A}_{2}$ (Figure 1). Over a decade ago, it was discovered that COX exists in two isoforms, COX-1 and COX-2, encoded by separate genes $[3,4]$. COX-1 and COX-2 are $60 \%$ homologous at both nucleic acid and amino acid sequence levels. The COX isoforms appear to differ from each other less in structure than in biologic effects. In general, although there are exceptions, COX-1 is constitutively expressed in most tissues, whereas COX-2 expression is rapidly induced during inflammation by a variety of agents, including cytokines, mitogens, and PGs [5].

Aspirin had been used as an anti-inflammatory agent for more than 100 years before its mechanism of action was attributed to inhibition of PG synthesis [6]. ASA irreversibly inhibits COX by acetylating Serine 530 at the apex of the long hydrophobic channel forming its active site, thereby excluding access of AA[7]. Nonselective nonsteroidal anti-inflammatory drugs (NSAIDs) inhibit the COX isoenzymes to different extents, accounting for their antiinflammatory and analgesic properties, as well as their gastrointestinal side effects. The selective COX-2 inhibitors were developed in an effort to create anti-inflammatory agents that would lack the COX-1 mediated gastrointestinal side effects and the risk of gastrointestinal bleeding associated with aspirin and NSAIDs[2].

\footnotetext{
Address correspondence to: MacRae F. Linton or Sergio Fazio, 383 PRB, 2220 Pierce Avenue, Vanderbilt University Medical Center, Nashville, TN 37232-6300, Tel: 615-936-1450, Fax: 615-936-3486, E-mail: macrae.linton@ vanderbilt.edu, sergio.fazio@vanderbilt.edu.

Publisher's Disclaimer: This is a PDF file of an unedited manuscript that has been accepted for publication. As a service to our customers we are providing this early version of the manuscript. The manuscript will undergo copyediting, typesetting, and review of the resulting proof before it is published in its final citable form. Please note that during the production process errors may be discovered which could affect the content, and all legal disclaimers that apply to the journal pertain.
} 


\section{Eicosanoids in cardiovascular physiology and atherothrombosis}

The synthesis of prostaglandins is relatively cell-specific and is modulated by factors such as inflammatory stimuli. PGs are produced by all of the major cell types involved in atherothrombosis and may impact atherogenesis through a variety of mechanisms (Figure 2). In general, one or two PGs are the predominant product of a given cell type. For example, platelets produce $\mathrm{TXA}_{2}$ via COX-1, but $\mathrm{TXA}_{2}$ is also produced by macrophages via COX-1 or COX-2 [8]. Platelet $\mathrm{TXA}_{2}$ promotes platelet aggregation and is a potent vasoconstrictor. The beneficial effects of aspirin on cardiovascular disease are likely due to its ability to reduce platelet aggregation through inhibition of COX-1-mediated production of platelet $\mathrm{TXA}_{2}$ [9].

$\mathrm{PGI}_{2}$ is the major eicosanoid produced by endothelial cells in vitro [10], and has antiplatelet, antiadhesive, vasodilatory and antiproliferative properties [11,12]. The biologic actions of $\mathrm{PGI}_{2}$ are mediated by the prostacyclin receptor (IP). $\mathrm{PGI}_{2}$ appears to play an important role protecting against elevated blood pressure, as deletion of the IP promotes salt sensitive hypertension and cardiac fibrosis in mice [13]. For many years, endothelial cell production of $\mathrm{PGI}_{2}$ was assumed to be mediated by COX-1, based on in vitro studies [14]. As discussed below, $\mathrm{COX}-2$ is the major contributor to systemic $\mathrm{PGI}_{2}$ as assessed by urinary metabolites of $\mathrm{PGI}_{2}$, but the relative contributions of COX-1 and COX-2 to endothelial production of $\mathrm{PGI}_{2}$ in vivo remain a subject of debate, with most evidence pointing to COX-1 as the main enzyme isoform involved [15]. This issue is relevant because a hypothesis that has received considerable attention over the years is that the balance between TX and $\mathrm{PGI}_{2}$ is an important determinant of hemostasis, thrombosis, and atherothrombosis. Increased cardiovascular events observed in the APPROVe trial[16] led to the removal of the selective COX-2 inhibitor rofecoxib from the market. COX-2 inhibition has been reported to alter the thrombotic response in several animal models[17,18], however, a number of studies in humans have shown that selective COX-2 inhibitors do not increase platelet or thrombotic activity[15,19]. Although the hypothesis that COX-2 inhibition tips the balance between $\mathrm{PGI}_{2}$ and $\mathrm{TX}$ has been invoked as a possible mechanism to explain this increase in cardiovascular events, it has fallen out of favor based on more recent data [8].

$\mathrm{PGE}_{2}$, a mediator of inflammation and pain, is a vasodilator, a natriuretic factor, an inhibitor of gastric acid secretion, and a regulator of uterine contraction [20]. It has been implicated in atherogenesis, vascular tone, and plaque rupture. $\mathrm{PGE}_{2}$ is a major product of activated macrophages. The biologic actions of $\mathrm{PGE}_{2}$ are complex, as its effects are mediated by four different prostanoid receptors (EP-1 - EP-4) that control different functions. EP-4 has been shown to be the primary mediator of anti-inflammatory effects of $\mathrm{PGE}_{2}$ in vitro[21,22]. EP-1 and EP-3 mediate PGE $_{2}$-induced vasoconstriction [23]. Deletion of EP-2 promotes saltsensitive hypertension $[13,24]$. In addition, $\mathrm{PGE}_{2}$ has been reported to activate platelets by EP-3, but it also can inhibit platelet aggregation via the IP at higher concentrations [25]. Furthermore, $\mathrm{PGE}_{2}$ stimulates activation of matrix metalloproteinase 9 (MMP 9) via EP-4 [26].

Relatively little is known about the role of $\mathrm{PGD}_{2}$ in atherothrombosis. In vitro evidence suggests that $\mathrm{PGD}_{2}$ can promote platelet activation. The biologic actions of $\mathrm{PGD}_{2}$ are mediated by the DP receptor. Interestingly, $\mathrm{PGD}_{2}$ release by Langerhans cells has been reported to mediate the cutaneous vasodilation caused by niacin [27]. Activated macrophages produce $\mathrm{PGD}_{2}$ in a COX-2 dependent manner following stimulation with LPS and PAF[28]. PGD2 is also the precursor of 15-deoxy-12,14-prostaglandin J2 (15-dPGJ2) a putative natural ligand for peroxisome proliferator-activated receptor- $\gamma(\operatorname{PPAR} \gamma)$. We have recently shown that elimination of macrophage PPAR $\gamma$ promotes atherosclerosis in a murine model of hyperlipidemia-induced atherosclerosis[29]. Activation of PPAR $\gamma$ may impact atherosclerosis through a variety of mechanisms, including inhibition of VSMC cell growth and migration, 
stimulation of VSMC apoptosis, and modulation of macrophage recruitment. However the in vivo relevance of 15-dPGJ2 as an agonist for PPAR $\gamma$ remains a subject of debate.

\section{Contributions of COX-1 and COX-2 to systemic $\mathrm{PGI}_{2}$ production}

Two elegant clinical studies by FitzGerald and coworkers have demonstrated that COX-2 expression contributes significantly to systemic prostacyclin synthesis. McAdam et al. reported that ibuprofen and celecoxib similarly inhibit urinary 2,3 dinor-6 keto PGF $_{1 \alpha}(\mathrm{PGI}-\mathrm{M})$, an index of extrarenal prostacyclin biosynthesis[30]. In a similar study of 36 adults, CatellaLawson et al. found that rofecoxib $50 \mathrm{mg}$ and indomethacin $50 \mathrm{mg}$ three times a day yield similar reductions in urinary excretion of PGI-M and 6-keto-PGF $1 \alpha$, an index of renal prostacyclin synthesis [31]. Also, Van Hecken et al. found that 12.5 and $25 \mathrm{mg}$ of rofecoxib inhibit urinary excretion of 6-keto-PGF $1 \alpha$, and PGI-M by 30-40\% in young healthy volunteers [32]. In contrast, Tuleja et al. reported that 7 days of treatment with rofecoxib $50 \mathrm{mg} / \mathrm{d}$ did not impact formation in blood of TX, $\mathrm{PGI}_{2}$, thrombin, or the bleeding time at the site of a standardized microvascular injury [33], suggesting that COX-2 is not the major source of $\mathrm{PGI}_{2}$ in the microvaculature and that the coxibs do not necessarily lead to reduced $\mathrm{PGI}_{2}$ production or alterations in the hemostatic balance [33].

Because endothelial cells are known to produce prostacyclin, the studies showing that COX-2 inhibition reduces urinary metabolites of $\mathrm{PGI}_{2}[30,31]$ have been extrapolated to infer that COX-2 inhibition may result in severe inhibition of endothelial cell prostacyclin production, possibly upsetting the putative balance between $\mathrm{TX}$ and $\mathrm{PGI}_{2}$ and promoting a prothrombotic state. However, it is important to point out that these studies did not directly address the major source of the "systemic" prostacyclin being reduced by COX-2 inhibition. COX-2 expression contributes to $\mathrm{PGI}_{2}$ production in a number of tissues including the forebrain, the macula densa of the kidney[34], and bronchiolar epithelium of normal lungs[35].

\section{COX-1 expression predominates in normal arteries and both COX isoforms are expressed in atheroma}

Immunocytochemical studies examining COX-1 and COX-2 expression in human arteries have shown that COX-1 is expressed abundantly in normal arteries and in atherosclerotic lesions, whereas COX-2 expression is restricted to atherosclerotic lesions[36-38]. Pratico reported that COX-2 mRNA is detectable in low levels in the aortas of 8-week old $\mathrm{LDLR}^{-1-}$ mice on a chow diet, and in higher levels in the setting of atherosclerosis induced by the Western diet. In contrast, COX-1 expression in the artery wall is apparently unchanged by development of dietinduced atheroscleorosis in $\mathrm{LDLR}^{-1-}$ mice[39]. Both COX-1 and COX-2 are expressed by endothelial cells, monocyte/macrophages and vascular smooth muscle cells in atherosclerotic lesions of humans[36,37] and in murine models[40]. Overall, these immunocytochemical studies show that COX-1 is the major isoform expressed in normal arteries, whereas both COX-1 and COX-2 are expressed in atherosclerotic lesions.

COX-2 has been reported to preferentially couple with prostacyclin synthase (PGIS) to promote prostacyclin synthesis[41]. To evaluate the extent of co-localization of PGIS and thromboxane synthase (TXS) with COX-1 and COX-2 in normal aortic endothelium, Kawka et al. performed extensive double-label immunofluorescence microscopy studies in arteries from dogs, rats and humans [35]. Significant co-localization of COX-1 and PGIS was demonstrated in the endothelium in all three species. In contrast, COX-2 was not detected in the human aorta, and was restricted to small foci of endothelial cells in the aortas of rats and dogs. Quantification of the total cross-sectioned aortic endothelium in dogs revealed a 6- to 7-fold greater expression of COX-1 relative to COX-2 (55 vs. 8\%) and greater co-distribution of PGIS with COX-1 compared to COX-2 (19 vs. 3\%)[35]. Treatment of rats with a selective COX-1 inhibitor 
(SC-560 $10 \mathrm{mg} / \mathrm{kg}$ ) caused striking reductions of 6-keto-PGF $1 \alpha$ and $\mathrm{TXB}_{2}$ levels in aortic tissue, whereas COX-2 inhibition (MF tricyclic $5 \mathrm{mg} / \mathrm{kg}$ ) had no significant effect. These results support earlier in vitro biochemical studies of the impact of selective COX-1 and COX-2 inhibition on aortic tissue from cholesterol fed rabbits demonstrating that AA-dependent $\mathrm{PGI}_{2}$ production by aortic tissues is largely mediated by COX-1[42]. Thus, these studies strongly support a much larger contribution of COX-1, relative to COX-2, to the synthesis of prostacyclin in aortic endothelium.

Studies demonstrating increased COX-2 expression in cultured endothelial cells in response to short-term exposure to shear stress have been invoked as evidence that COX-2 expression in the endothelium should be up-regulated by shear forces in vivo[43,44]. However, studies of the impact of shear forces on expression of COX-2 have been mixed with some studies showing marked increases in expression of COX-1 and not COX-2 and others showing that COX-2 expression is not increased after long term exposure to shear stress for 1 to 7 days[14]. To investigate the impact of shear on co-localization of COX-2 and PGIS, Kawka et al. examined the distribution of their co-expression using dual immunofluorescence in areas of vascular endothelium that are frequently subjected to high shear stress and found no evidence for increased COX-2 in areas of high shear stress[35]. Thus, the data do not support the concept that COX-2 expression by endothelial cells is the major source of prostacyclin in normal arteries in vivo even in areas of high shear stress.

Endothelial cells play a crucial role in maintaining arterial health by producing a number of factors that promote vasodilation and reduced platelet adhesion, such as nitric oxide[45] and prostacyclin [46]. Injury to the arterial wall is believed to cause endothelial dysfunction, one of the initial steps in the development of atherothrombosis. There are a number of approaches to assess endothelial dysfunction in vivo, but most depend on the finding of impaired endothelium-dependent vasodilation in response to various challenges. Mediators of endothelium-dependent vasodilation include $\mathrm{NO}, \mathrm{PGI}_{2}$, and endothelium-derived hyperpolarizing factors[46]. If COX-2 plays a critical role in mediating $\mathrm{PGI}_{2}$ production by arterial endothelial cells in vivo, one would anticipate that treatment with COX-2 inhibitors might result in impaired endothelium-dependent vasodilation. In contrast, five studies in humans have found no impact of COX-2 inhibition on endothelium-dependent vasodilation [47-51], whereas two studies actually found that treatment with COX-2 inhibitors improved endothelium-dependent vasodilation[52,53]. In summary, the studies investigating COX-2 inhibition and endothelial function in humans in vivo have found either no impact or a beneficial effect.

Interestingly, McAdam et al. have recently reported that healthy male smokers have elevated urinary PGI-M levels and that treatment with rofecoxib $25 \mathrm{mg}$ bid for 7 days resulted in a 59\% reduction in PGI-M in smokers and a 51\% reduction in nonsmokers $(p=0.03)$ [54]. Excretion of the urinary metabolite of TXA2, 11-dehydrothromboxane $\mathrm{B}_{2}$ (TX-M), was elevated in smokers compared to nonsmokers, and treatment with rofecoxib reduced the levels of TX-M by $21 \%$ in smokers but did not change the levels of TX-M in nonsmokers. The authors concluded that the increased biosynthesis of $\mathrm{PGI}_{2}$ in smokers is derived from COX-2. Furthermore, COX-2 contributes to the increased biosynthesis of $\mathrm{TXA}_{2}$ in smokers, but this increase likely derives from inflammatory cells, such as monocyte/macrophages, not platelets. An accompanying editorial pointed out how these results by McAdam et al. challenge the paradigm that the balance between platelet TX and endothelial $\mathrm{PGI}_{2}$ is a critical determinant of atherothrombosis[55]. Recent studies by our laboratory have demonstrated that elimination of COX-1 gene expression in bone marrow-derived cells eliminates platelet TX but does not reduce atherosclerosis in $\mathrm{LDLR}^{-/-}$mice, demonstrating that platelet TX is not a driving force in atherogenesis in murine models and that the balance between TX and $\mathrm{PGI}_{2}$ is not a critical determinant of atherosclerosis[56]. This is in agreement with a recent authoritative review by 
Dr. FitzGerald, stating that "...the concept of simply tipping a "balance" between COX-2 derived $\mathrm{PGI}_{2}$ and COX-1 derived platelet thromboxane is misplaced." [8]

\section{Non-Selective Inhibition of COX Reduces Atherosclerosis in Animal Models}

The beneficial effects of low-dose aspirin in the secondary prevention of cardiovascular events are believed to be due to inhibition of platelet aggregation through inhibition of platelet $\mathrm{TXA}_{2}$ [57-59]. Aspirin has been shown to reduce the progression of coronary atherosclerosis [60], the frequency of clinical events in patients with chronic stable angina [61], and myocardial infarction in men with high levels of CRP in plasma [62]. It has been suggested that some of the beneficial effects of aspirin on coronary events may stem from its anti-inflammatory effects [63]. More than three decades ago, NSAIDs were reported to decrease atherosclerosis in cholesterol fed rabbits, indicating that nonselective COX inhibition reduces atherosclerosis in this animal model [64]. Recent studies in mice have confirmed these early studies by showing that nonselective inhibition of COX results in dramatic reductions in atherosclerosis in $\mathrm{LDLR}^{-1-}$ mice[39,40]. Interestingly, the beneficial impact on atherosclerosis was accompanied by a $90-95 \%$ reduction in urinary 2,3-dinor TxB2 and near total elimination of systemic $\mathrm{PGI}_{2}$ production, demonstrating that beneficial therapeutic effects on atherosclerosis can be obtained when $\mathrm{PGI}_{2}$ is virtually absent. In contrast, non-selective COX inhibition with indomethacin in apobec-1/LDLR ${ }^{-/-}$mice reduced urinary 2,3 -dinor TxB 2 only by about $66 \%$ and did not reduce the extent of atherosclerosis, possibly due to the uniqueness of this model [65].

\section{COX-2 in atherosclerosis}

Atherosclerosis, the underlying cause of coronary heart disease and stroke, is widely regarded as an inflammatory disease process [66]. All of the major cell types involved in atherogenesis produce eicosanoids and their impact on atherogenesis and plaque stability may vary according to lesion stage. Thus the role of COX-2 in atherogenesis is likely complex as its effects are mediated by a variety of eicosanoids with both pro- and anti-atherogenic effects that may vary during the evolution of the plaque. Studies examining the impact of COX-2 inhibition on atherosclerosis have generated conflicting evidence indicating that COX-2 inhibition can accelerate, decrease or have no impact on atherosclerosis [39,40,67-69]. The differences in the results of these studies may be explained by the pharmacological differences of the inhibitors (e.g. efficacy and selectivity), gender of the mice, genetics of the murine model, and atherosclerotic lesion stage[70]. We have previously reported that rofecoxib reduces early atherosclerotic lesion formation in $\mathrm{LDLR}^{-/-}$mice fed a Western type diet for 8 weeks [40]. Pratico and colleagues have shown that treatment of $\mathrm{LDLR}^{-1-}$ mice fed a Western type diet for 18 weeks with the COX-2 selective inhibitor nimesulide resulted in a trend for a $30 \%$ reduction in atherosclerosis which failed to reach statistical significance [39]. Subsequently, we found significant reductions in early atherosclerosis in 8-week-old chow-fed female apoE $^{-/-}$mice treated with selective the COX-2 inhibitors rofecoxib or NS398 or nonselective COX inhibition with indomethacin[71]. Similarly, Krul and coworkers have presented data demonstrating that 6 -week-old apoE deficient mice fed a diet containing $0.125 \%$ cholesterol for 12 weeks treated with celecoxib had a significant $22 \%$ reduction in aortic atherosclerosis. Recently, Jacob et al. have reported that treatment of 4-wk old apoE ${ }^{-/-}$mice with a standard rodent diet supplemented with $900 \mathrm{ppm}$ of celecoxib for $16 \mathrm{wk}$ led to an $81 \%$ reduction in lesion size[72]. These results are consistent with our findings in $\mathrm{LDLR}^{-/-}$and $\mathrm{apoE}^{-/-}$mice and provide further evidence that treatment with selective COX-2 inhibitors reduces early atherosclerotic lesion formation in murine models.

Two studies of the impact of COX-2 inhibition on atherosclerosis in mice have reported an increase in atherosclerosis[68,73]. Rott et al. reported that MF-tricyclic treatment of 8-week 
old apoE deficient mice for 3 weeks increases lesion area by $84 \%$ in noninfected mice and 70 $80 \%$ in CMV infected mice[68]. Interpretation of these results is limited by the fact that the gender and genetic background of the apoE deficient mice used were not specified [68]. In addition, this dramatic increase was found after only 3 weeks of treatment, an extremely short time frame for detecting differences in atherosclerosis in this model, raising questions about the physiological relevance of the observation. Furthermore, two other MF tricyclic studies of longer duration showed no effect $[65,67]$. Metzner et al. treated 6-week-old female apoE ${ }^{-/-}$ mice with celecoxib(25 mg/kg Bid), rofecoxib(10 mg/kg Bid), naproxen(10 mg/kg Bid), or vehicle for 16 weeks in the setting of either a normal chow or Western-type diet[73]. No differences were seen between any of the groups fed the Western diet. In the setting of a normal chow diet, they reported a small but significant increase in atherosclerosis in the group treated with celecoxib, whereas the impact of rofecoxib was not statistically significant[73].

Interpretation of these results is limited by the relatively small number of mice examined per group $(\mathrm{n}=5)$ and the unusual approach used for analysis of atherosclerosis, which was defined as mean lumen constriction (the percentage of plaque size versus the total vessel lumen). Using this approach, no lesions were detected in the control apoE $\mathrm{E}^{--}$mice, which calls the sensitivity of the method into question given that 22-week old chow-fed apoE ${ }^{-/-}$mice have extensive atherosclerotic lesions[74,75]. Three more studies indicate that the ability of selective inhibition of COX-2 to impact atherogenesis is limited in the setting of advanced atherosclerotic lesions in apoE ${ }^{-/-}$mice $[67,69,76]$. Olesen et al. examined the effects of MFTricyclic (12 mg/kg/day) and a nonselective COX-2 inhibitor, sulindac, in male chow-fed, 6month-old apo $\mathrm{E}^{-/-}$mice [67] and found with no differences between the groups in the size of these extremely advanced atherosclerotic lesions. Bea et al. administered celecoxib (75 mg/ $\mathrm{kg} /$ day) in chow to 26 -week-old, male, apoE ${ }^{-1-}$ mice for 15 weeks and detected no significant changes in atherosclerosis in the innominate artery [69]. Belton et al. saw no effect of SC-236, a COX-2 selective inhibitor, on atherosclerosis in $\mathrm{apoE}^{-1-}$ mice made severely hypercholesterolemic by feeding a $1 \%$ cholesterol diet, conditions likely to induce more advanced lesions [76]. Furthermore, COX-2 inhibition failed to alter the progression of diffuse established atherosclerosis in mice deficient for apobec-1/LDLR double KO mice[65]. In this study, COX-2 inhibition appeared to increase plaque destabilization only when used in combination with the thromboxane receptor antagonist S18886 [65]. Although genetically altered mice are widely used in the study of atherosclerosis, a major limitation of this model is the fact that mice are resistant to developing plaque rupture and thrombosis. Therefore, the physiological relevance of changes in atherosclerotic plaque morphology, which are described as appearing to increase plaque destabilization, is uncertain.

The role of COX-2 in atherosclerosis is complex and may vary according to the cell type and lesion stage. We have reported that COX-2 is expressed in atherosclerotic lesions in the $\mathrm{apoE}^{-/-}$mouse[40]. A few monocyte/macrophages at the periphery of the lesion express COX-2 while the majority of macrophage-derived foam cells do not. These results are consistent with our observations in $\mathrm{LDLR}^{-/-}$mice [40] and with in vitro observations that oxidized LDL suppresses COX-2 expression in human macrophages [77]. Joseph and colleagues have reported a reciprocal regulation of inflammation and lipid homeostatic mechanisms in macrophages in response to liver $\mathrm{X}$ receptor (LXR) agonists [78], suggesting that oxysterols from oxLDL may induce LXR-mediated downregulation of COX-2 expression in macrophage-derived foam cells [78]. Through antagonism of NFKB signaling, LXR ligands inhibit the expression of proinflammatory genes including iNOS, COX-2, and IL-6 by macrophages activated with LPS in vitro [78]. Thus, macrophage foam cell formation may in some ways represent attenuation of the inflammatory response in atherogenesis in an effort to marshal the forces to deal with the toxic cholesterol load. Hence, the beneficial impact of COX-2 inhibitors on atherogenesis may be lost in advanced lesions due to LXR-mediated downregulation of COX-2 in macrophage-derived foam cells [78] or through inhibition of antimitogenic effects of COX-2 expression in smooth muscle cells [79]. If COX-2 inhibition 
promotes SMC proliferation in atherosclerotic lesions, one would expect to see an increase in atherosclerotic lesion area and SMC content in advanced atherosclerotic lesions, but these effects have not been observed[67,69,76].

\section{COX-2 Gene Deficiency in Bone Marrow-Derived Cells is Antiatherogenic}

Transplantation studies using bone marrow or fetal liver cells (FLC) (the major source of hematopoietic stem cells in developing fetus) from gene-targeted mice have been used to examine the role of various genes expressed by macrophages and bone marrow-derived cells in atherogenesis [80-82]. To examine the role of macrophage COX-2 gene expression in atherosclerosis, $\mathrm{LDLR}^{-/}$mice were transplanted with $\mathrm{COX}-2^{-/-}$or $\mathrm{COX}-2^{+/+} \mathrm{FLC}$ and then fed the Western diet for 8 weeks, inducing fatty streak lesions that consisted primarily of macrophage-derived foam cells. The atherosclerotic lesion area in $\mathrm{LDLR}^{-/-}$mice reconstituted with macrophages null for the COX-2 gene was significantly reduced (33-39\%) compared to the mice transplanted with COX-2 ${ }^{+/+}$FLC[40]. Similar studies in C57BL/6 mice reconstituted with either $\mathrm{COX}-2^{+/+}$or $\mathrm{COX}-2^{-/-}$FLC showed that, after a 14-week butterfat diet challenge, there was a 51\% reduction in atherosclerotic lesion formation in COX-2 $2^{-1-} \rightarrow \mathrm{C} 57 \mathrm{BL} / 6$ mice [71]. These results provide genetic evidence demonstrating that monocyte/macrophage COX-2 promotes early atherosclerotic lesion formation.

The transplantation studies implicate macrophage COX-2 in promoting early atherogenesis. It is well established that activated macrophages express COX-2 abundantly [83,84], whereas macrophage-derived foam cells do not [40]. Thus, the reduction in atherosclerosis seen in the transplant studies is likely due to an effect of COX-2 expression on atherogenesis prior to foam cell formation. Activation of macrophages by IFN $\gamma$, LPS, or IL- $1 \beta$ induces expression of COX-2 [85], resulting in the production of eicosanoids including $\mathrm{TXA}_{2}$ and $\mathrm{PGE}_{2}$, which modulate the inflammatory response. LPS-mediated activation of monocytes stimulates expression of COX-2 and a variety of chemokines, including MCP-1, IL-8, and MIP-1. Interestingly, lack of Toll-like receptor 4, a receptor for LPS, reduces atherosclerosis in apoE deficient mice and is associated with reduced COX-2 and MCP-1 in the lesions [86]. We have found that MCP-1 expression is decreased in LPS activated COX-2 deficient macrophages compared to wildtype peritoneal macrophages. Thus COX-2 might promote early atherogenesis through MCP-1 mediated recruitment of activated monocyte/macrophages [87]. Prostaglandins may also stimulate expression of inflammatory cytokines. $\mathrm{PGE}_{2}$ has been shown to induce production of the inflammatory cytokine IL-6 [88]. We have demonstrated a role for COX-2 in promoting TNF $\alpha$ expression from activated macrophages. TNF $\alpha$ can promote monocyte recruitment into early atherosclerotic lesions [89,90], and its impact is lost in more advanced lesions [91,92]. Thus, macrophage COX-2 may influence early atherogenesis through an impact of TNF $\alpha$ on monocyte recruitment and possibly by other effects on the inflammatory cytokine cascade.

\section{COX-2 and Abdominal Aortic Aneurysm Formation}

Arterial aneurysms are areas of pathological dilation of the artery that pose many of the same risks as atherosclerotic vascular disease by threatening life, limb and the function of vital organs [93]. Furthermore, arterial aneurysms share many of the same risk factors as atherosclerotic vascular disease, including hypercholesterolemia, hypertension, cigarette smoking, and age. In addition, aneurysms and atherosclerosis often co-exist in the same area of the artery. Traditionally, atherosclerosis is seen as the process responsible for initiation of aneurysm formation, but mounting evidence supports the involvement of other mechanisms including altered tissue metalloproteinases, the renin-angiotensin system, and inflammation. The discovery that infusion of angiotensin II into hypercholesterolemic mice leads to formation of abdominal aortic aneurysms (AAA) by Daugherty and coworkers [94] has led to intensive 
research into the molecular mechanisms of aneurysm formation using this model. Interestingly, COX-2 inhibition reduces the formation of AAA in mice, whereas COX-1 inhibition has no effect[95]. Recently, COX-2 gene expression has been reported to be required for angiotensin II-induced AAA formation in COX-2 $2^{+/+}$mice vs. COX- $2^{-/-}$mice on a C57BL6J/129/Ola hybrid background [96]. These results demonstrate that COX-2 expression plays a fundamental role in the formation AAA induced by angiotensin, supporting the potential for COX-2 inhibition in the prevention and treatment of AAA, a vascular disease process sharing many risk factors and pathogenic mechanisms with atherosclerosis.

\section{Genetic Deficiency of IP Modulates Vascular Response to Injury and Atherosclerosis}

Disruption of the gene for the prostacyclin receptor (IP) in mice has been found to result in increased intima/media ratio in response to vascular injury, indicating a protective role for endothelial prostacyclin in vascular remodeling by smooth muscle cells in response to injury [97]. Recently, Cheng and colleagues published a set of experiments further examining the dichotomy of prostacyclin and thromboxane in a mouse model of vascular injury [97]. The study used digital methods to quantify intimal thickening and cell proliferation in response to catheter induced endothelial denudation of the carotid artery. Mice deficient (KO) for receptors for prostacyclin (IP), thromboxane (TP), both (IPTP), or transgenic overexpressors of hTP gprotein coupled receptors were generated for this experiment. Background strains were B6/129, $\mathrm{Balb} / \mathrm{c}, 129$, and B6SJLF for IPKO, TPKO, IPTPDKO, and transgenics, respectively, raising concerns that differences in genetic background may have influenced susceptibility to vascular response to injury. A significant increase in intima/media ratio was observed on disruption of the IP receptor gene. Conversely, a significant decrease in intima/media ratio was observed on disruption of the TP receptor gene. The difference in response to vascular injury was abolished in the DKO mice. The intima/media ratio was increased significantly in transgenic mice overexpressing the hTP receptor in response to vascular injury when compared to TP wildtype littermates. The effect of hTP overexpression on the intima/media ratio was abolished on oral administration of S18886, a long acting TP receptor antagonist. The data support protective and deleterious effects of prostacyclin and thromboxane, respectively, in the pathology of smooth muscle cell proliferation in response to endothelial injury of the carotid artery. These studies did not directly address the role of COX-2 in atherosclerosis or the response to endothelial injury.

Kobayashi et al. reported that elimination of the IP in apoE deficient mice accelerates the development of atherosclerosis [98]. In addition, Eagen et al. reported that female (but not male) $\mathrm{LDLR}^{-/-} \mathrm{IP}^{-/-}$double knockout mice develop increased atherosclerosis and urinary $\mathrm{TX}$ levels compared to $\mathrm{LDLR}^{-/} \mathrm{IP}^{+/+}$[99]. The main point of this paper is that deletion of the IP removed the atheroprotective effect of estrogen in ovariectomized female mice. It is important to realize that in murine models of atherosclerosis female mice are uniformly more susceptible to atherosclerosis than males, raising questions about the relevance of these findings to human disease, where the male gender confers higher risk for cardiovascular events. Interestingly, the extent of atherosclerosis was not different in female $\mathrm{LDLR}^{-/} \mathrm{IP}+/-$ vs. $\mathrm{LDLR}^{-/} \mathrm{IP}^{-/-}$mice [99]. Thus, partial loss of IP expression did not increase atherosclerosis. This is in contrast with the results from a recent study by Cheng et al.[100], showing a gene dosage effect of IP on the development of thrombosis in response to photochemical injury. The time to complete occlusion of the carotid artery after rose Bengal dye injection was reduced in $\mathrm{IP}^{-/-}$mice vs. WT mice and the results for $\mathrm{IP}^{-/+}$mice were intermediate. Treatment with the COX-2 inhibitor DFU also reduced time to occlusion in this model to an extent that was intermediate between the results in $\mathrm{IP}^{-/}$and IP-/+ mice and was partially attenuated by knockdown of COX-1. Interpretation of these results is limited by the fact that selectivity data was presented for celecoxib, and not DFU, and the fact that the COX-1 ko mice were on a hybrid background 
(DBA/1lacJ or DBA/1lacJ $\times$ C57BL/6.) Overall the studies in IP KO mice show an important role for the IP and its ligands in modulating vascular response to injury and atherogenesis, but it is perhaps an oversimplification to equate these results with COX-2 inhibition, given that COX-1 makes a major contribution to PGI2 production and COX-2 mediates production of a variety of eicosanoids in the artery wall. Thus, it is unlikely that the IP mediates all the effects of COX-2 mediated eicosanoid production that are relevant in atherosclerosis and the vascular response to injury.

\section{COX-1, Platelet TXA2, TP and Atherosclerosis}

COX-1 has been proposed to promote the development of atherosclerosis in $\mathrm{LDLR}^{-/}$mice based on the observation that the nonselective inhibitor indomethacin significantly reduced atherosclerosis, whereas the selective COX-2 inhibitor nimesulide produced a nonsignificant trend for a reduction in lesion area[39]. Belton et al. have implicated COX-1 in promoting the early stages of lesion formation, because treatment of apoE ${ }^{-1-}$ mice fed a $1 \%$ cholesterol diet with the selective COX-1 inhibitor SC-560 for 8-weeks dramatically reduced atherosclerotic lesion formation, whereas SC-560 did not induce regression or inhibit progression of established lesions[76]. Although SC-560 did not prevent platelet adhesion in these studies, Belton et al. suggested that the most likely explanation for the reduction in atherosclerosis was inhibition of platelet activation due to inhibition of COX-1 mediated-platelet $\mathrm{TXA}_{2}$ generation. Genetic deficiency in the $\mathrm{TXA}_{2}$ receptor suppresses vascular proliferation and platelet activation in an arterial injury-induced model of neointimal hyperplasia in mice[97], and inhibits atherosclerosis in apoE ${ }^{-/-}$mice[98]. Similarly, the administration of the $\mathrm{TXA}_{2}$ antagonist S-18886 suppresses the development of atherosclerotic lesions in $\operatorname{apoE}^{-/-}$mice $[65,101]$. However, aspirin was more efficient than S-18886 in TX inhibition but only had slight effects on the development of atherosclerosis, suggesting that a mechanism independent of platelet-derived TX is responsible for suppression of the development of atherosclerosis [101]. Thus, COX-1 has been reported to promote atherosclerosis in murine models, and COX-1-mediated platelet $\mathrm{TXA}_{2}$ production has been proposed to be responsible for the proatherogenic effects of COX-1 in early lesion formation. However, this hypothesis had not been tested directly until our laboratory examined the impact of eliminating COX-1 expression in the bone marrow of two different mouse models on early atherogenesis.

In order to examine the impact of COX-1 gene expression by bone marrow-derived cells on the development of atherosclerosis, $\mathrm{LDLR}^{-/-}$and $\mathrm{apoE}^{-/-}$mice were lethally irradiated and transplanted with $\mathrm{COX}_{-1} 1^{-/-}$or $\mathrm{COX}-1^{+/+}$bone marrow[56]. In recipient mice reconstituted with $\mathrm{COX}-1^{-/-}$bone marrow-derived cells, platelet $\mathrm{TXA}_{2}$ production was virtually eliminated and production of urinary and macrophage $\mathrm{TXA}_{2}$ metabolites were significantly reduced. Surprisingly, mice reconstituted with $\mathrm{COX}^{-1}{ }^{-/-}$bone marrow had increased atherosclerotic lesions in the absence of significant differences in serum lipids. These data demonstrate that COX-1-mediated platelet $\mathrm{TXA}_{2}$ production is not a major driving force in early atherosclerotic lesion formation. Hence, any possible beneficial effects of the loss of platelet TX in early atherogenesis must be outweighed either by the loss of production of antiatherogenic COX-1mediated eicosanoids from bone marrow-derived cells, production of proatherogenic COX-1mediated eicosanoids by vascular cells, and or by a proatherogenic effect mediated by compensatory upregulation of COX-2 expression in macrophages. We found evidence for compensatory upregulation of COX-2 in $\mathrm{COX}-1^{-1-}$ macrophages[56]. Furthermore, elimination of both COX-1 and COX-2 in bone marrow-derived cells of LDLR deficient mice eliminates the increase in atherosclerosis attributable to deficiency of COX-1 in bone marrowderived cells, providing strong support for a proatherogenic role of macrophage COX-2 expression[56]. Hence, COX-2 expression contributes significantly to the increased atherosclerosis in mice reconstituted with COX-1 null bone marrow-derived cells. Although complete elimination of the TP in apoE deficient mice results in significant reduction in 
atherosclerosis[98], a more recent report from the same group demonstrates that elimination of the TP in bone marrow-derived cells in apoE deficient mice is not associated with a reduction in atherosclerosis[102]. Thus, expression of TP on platelets and bone marrow-derived cells does not contribute to the promotion of atherosclerosis. Therefore, it will be important to examine the roles of COX-1, TX production, and TP expression by cells of the vascular wall in atherogenesis. Given our finding of increased early atherogenesis in the face of a dramatic reduction in urinary and platelet TX with no change in urinary $\mathrm{PGI}_{2}$, these results indicate that the balance between $\mathrm{TX}$ and $\mathrm{PGI}_{2}$ is not a critical determinant of early atherosclerotic lesion formation.

\section{PGE2 and mPGES-1 in atherosclerosis and plaque destabilization}

Three synthases have been identified that produce PGE2: cPGES, mPGES-1 and mPGES-2 [103]. FitzGerald and coworkers have recently examined the impact of deleting one of the PGE synthase (PGES) enzymes, microsomal PGES-1 in LDLR deficient mice[104]. mPGES-1 is inducible by inflammation and may be coordinately regulated with COX-2[103].

Atherosclerotic lesion area was significantly reduced in both male and female mPGES- ${ }^{-1}{ }^{-}$LDLR $^{-1-}$ mice fed a high fat diet compared to LDLR-I- control mice, but blood pressure was not altered[104]. The atherosclerotic plaques showed reduced macrophage content, but the total areas occupied by vascular smooth muscle and extracellular matrix were not changed. However, the atherosclerotic lesions of mPGES- $1^{-1-} \mathrm{LDLR}^{-1-}$ mice were enriched in fibrillar collagens, a hallmark of plaque stabilization. In contrast, there was no evidence for increased fibrous cap formation. Elimination of mPGES-1 caused increased expression of $\mathrm{PGI}_{2}$ and TX to varying degrees in endothelial cells, macrophages and VSMC. Urinary PGE-M was depressed, whereas urinary 2,3-dinor 6-keto PGF1, but not 2,3-dinorTxB2, was increased in mPGES- ${ }^{-/-} \mathrm{LDLR}^{-/-}$mice. The authors suggest that the impact of deletion of mPGES-1 on atherogenesis may be due in part to rediversion of accumulated $\mathrm{PGH}_{2}$ to augment formation of $\mathrm{PGI}_{2}$ [104]. Although this is an intriguing and tenable hypothesis, the studies do not rule out the possibility that $\mathrm{PGE}_{2}$ mediates important effects on atherogenesis directly, and this study highlights the need for a better understanding of the $\mathrm{E}$ prostanoid receptors in atherogenesis.

Cipollone and coworkers have demonstrated enhanced expression of COX-2 and PGE synthase-1 (COX-2/mPGES-1) in human symptomatic plaques, and provided evidence that it is associated with MMP-induced plaque rupture. In a study of carotid endarterectomy specimens from 50 patients, COX-2, PGE synthase (PGES), and MMPs were especially noted in shoulders of symptomatic plaques, colocalizing with HLA-DR+ macrophages, and all of the symptomatic plaques contained activated forms of MMPs[105]. In other immunocytochemical studies of carotid endarterectomy specimens, pretreatment with simvastatin $40 \mathrm{mg}$ for 4 months decreased inflammation and inhibited COX-2/mPGES expression in plaque macrophages[106]. Based on these results the authors suggested that inhibition of COX-2-mediated $\mathrm{PGE}_{2}$ production by statins may contribute to plaque stabilization by inhibition of MMP-induced plaque rupture. Similarly, blockade of the angiotensin II type 1 receptor by treatment with irbesartan has been reported to stabilize atherosclerotic plaques in humans by inhibiting $\mathrm{PGE}_{2}$-dependent matrix metalloproteinase activity[107]. The balance between COX-2 mediated production of $\mathrm{PGD}_{2}$ and $\mathrm{PGE}_{2}$ via their respective synthases has been proposed to be an important determinant of plaque rupture [108], and the EP-4 receptor for $\mathrm{PGE}_{2}$ has been shown to be responsible for the $\mathrm{PGE}_{2}$-mediated increase in MMP activity in unstable plaques[109]. Cipollone et al. have described a functional genetic polymorphism in the COX-2 gene that reduces the risk of myocardial infarction, possibly through reduced COX-2-mediated $\mathrm{PGE}_{2}$-stimulated production of MMPs by macrophages [110]. Thus, although much attention has been given to the roles of PGI2 and 
TX in atherothrombosis, a growing body of evidence supports roles for $\mathrm{PGE}_{2}$ in atherogenesis and plaque rupture.

\section{Summary}

Prostaglandins and their receptors may impact atherothrombosis through a variety of mechanisms by modulating: 1 ) production of anti- and proinflammatory cytokines; 2) immune responses; 3) inflammatory cell recruitment and migration; 4) vascular smooth muscle cell migration and proliferation; 5) modulation of vascular tone and blood pressure; 6) activation of MMPs; 7) platelet adhesion and aggregation. All of the major cell types involved in atherogenesis produce eicosanoids, and their impact on atherogenesis, plaque stability, and thrombosis may vary according to lesion stage. The removal of rofecoxib from the market due to increased cardiovascular event rates observed in the APPROVe Trial, emphasizes our need for a better understanding of the roles of PGs in atherothrombosis. In animal models, nonselective inhibition of COX reduces atherosclerotic lesion formation, whereas the results of COX-2 inhibition have been mixed with studies showing increased, decreased or no impact on lesion area. Treatment with COX-2 inhibitors reduced early atherosclerotic lesion formation in several studies, as did elimination of COX-2 expression in bone marrow derived cells, whereas studies of advanced lesions uniformly showed no impact. However, either COX-2 inhibition or COX-2 gene deletion have a profound ability to prevent angiotensin II-induced aneurysm formation in mice. Recent studies of the impact of genetic deletion of specific prostaglandin receptors in murine models have provided important insights into the roles of several of these receptors in atherothrombosis. The beneficial effect of aspirin in reducing cardiovalscular events is widely attributed to inhibition of COX-1 mediated platelet TX production. Interestingly, deletion of the TP in mice reduces atherosclerosis in apoE deficient mice. However, the reduced atherosclerosis cannot be attributed to inhibition of platelet TX production, because BMT studies have shown that elimination of COX-1 or TP expression in bone marrow-derived cells does not reduce atherosclerosis. A number of studies have shown that genetic deletion of the IP accelerates the vascular response to injury and atherosclerosis. However, equating the impact of IP deletion on atherogenesis to COX-2 inhibition, seems likely an oversimplification, given the diverse roles of PGs in atherothrombosis. Reducing $\mathrm{PGE}_{2}$ production through genetic deletion of microsomal PGES-1 reduces atherosclerosis highlighting the need for studies of the roles of the EPs in atherogenesis. A more detailed understanding of the roles of prostaglandins and their receptors in atherothrombosis may point to more specific targets for the prevention of atherosclerotic cardiovascular disease.

\section{Acknowledgements}

The authors would like to thank Edward F. Linton for assistance with the figures. M.F.L. and S.F. are supported by National Institutes of Health grants HL65405, HL57986, HL86988, HL65709.

\section{References}

1. Smith WL, Marnett LJ. Prostaglandin endoperoxide synthase: structure and catalysis. Biochim Biophys Acta 1991;1083:1-17. [PubMed: 1903304]

2. DuBois RN, et al. Cyclooxygenase in biology and disease. FASEB J 1998;12:1063-1073. [PubMed: 9737710]

3. Raz A, et al. Regulation of fibroblast cyclooxygenase synthesis by interleukin-1. Journal of Biological Chemistry 1988;263(6):3022-3028. [PubMed: 3125173]

4. Reed DW, et al. In vivo and in vitro expression of a non-mammalian cyclooxygenase-1. Prostaglandins 1996;52(4):269-284. [PubMed: 8936583]

5. Wu KK. Cyclooxygenase-2 induction in congestive heart failure friend or foe? Circulation 1998;98:9596. [PubMed: 9679712] 
6. Vane JR. Inhibition of prostaglandin synthesis as a mechanism of action for aspirin-like drugs. Nature - New Biology 1971;231(25):232-235.

7. Picot D, et al. The X-ray crystal structure of the membrane protein prostaglandin $\mathrm{H} 2$ synthase-1.[see comment]. Nature 1994;367(6460):243-249. [PubMed: 8121489]

8. Grosser T, et al. Biological basis for the cardiovascular consequences of COX-2 inhibition: therapeutic challenges and opportunities. J Clin Invest 2006;116(1):4-15. [PubMed: 16395396]

9. Hennekens $\mathrm{CH}$, et al. Aspirin as a therapeutic agent in cardiovascular disease: a statement for healthcare professionals from the American Heart Association. Circulation 1997;96(8):2751-2753. [PubMed: 9355934]

10. Moncada $\mathrm{S}$, et al. Human arterial and venous tissues generate prostacyclin (prostaglandin $\mathrm{x}$ ), a potent inhibitor of platelet aggregation. Lancet 1977;1(8001):18-20. [PubMed: 63657]

11. Vane JR. Inhibitors of prostaglandin, prostacyclin, and thromboxane synthesis. Advances in Prostaglandin \& Thromboxane Research 1978;4:27-44. [PubMed: 417572]

12. FitzGerald GA, Patrono C. The Coxibs, selective inhibitors of cyclooxygenase-2. N Engl J Med 2001;345:433-442. [PubMed: 11496855]

13. Francois $\mathrm{H}$, et al. Prostacyclin protects against elevated blood pressure and cardiac fibrosis.[see comment]. Cell Metabolism 2005;2(3):201-207. [PubMed: 16154102]

14. Mitchell JA, Warner TD. COX isoforms in the cardiovascular system: understanding the activities of non-steroidal anti-inflammatory drugs. Nature Reviews Drug Discovery 2006;5(1):75-86.

15. Flavahan NA. Balancing prostanoid activity in the human vascular system. Trends in Pharmacological Sciences 2007;28(3):106-110. [PubMed: 17276520]

16. Bresalier RS, et al. Cardiovascular events associated with rofecoxib in a colorectal adenoma chemoprevention trial.[see comment][erratum appears in N Engl J Med. 2006 Jul 13;355(2):221]. New England Journal of Medicine 2005;352(11):1092-1102. [PubMed: 15713943]

17. Hennan JK, et al. Effects of selective cyclooxygenase-2 inhibition on vascular responses and thrombosis in canine coronary arteries. Circulation 2001;104(7):820-825. [PubMed: 11502709]

18. Pidgeon GP, et al. Intravascular thrombosis after hypoxia-induced pulmonary hypertension: regulation by cyclooxygenase-2. Circulation 2004;110(17):2701-2707. [PubMed: 15492320]

19. Steffel J, et al. Cyclooxygenase-2 inhibition and coagulation. Journal of Cardiovascular Pharmacology 2006;47(Suppl 1):S15-20. [PubMed: 16785824]

20. Cook JA. Eicosanoids. Critical Care Medicine 2005;33(12 Suppl):S488-491. [PubMed: 16340430]

21. Takayama K, et al. Prostaglandin E2 suppresses chemokine production in human macrophages through the EP4 receptor. J Biol Chem 2002;277(46):44147-44154. [PubMed: 12215436]

22. Takayama K, et al. A novel prostaglandin E receptor 4-associated protein participates in antiinflammatory signaling. Circulation Research 2006;98(4):499-504. [PubMed: 16424369]

23. Norel X, et al. Vasoconstriction induced by activation of EP1 and EP3 receptors in human lung: effects of ONO-AE-248, ONO-DI-004, ONO-8711 or ONO-8713. Prostaglandins \& Other Lipid Mediators 2004;74(1-4):101-112. [PubMed: 15560119]

24. Kennedy CR, et al. Salt-sensitive hypertension and reduced fertility in mice lacking the prostaglandin EP2 receptor. Nature Medicine 1999;5(2):217-220.

25. Fabre JE, et al. Activation of the murine EP3 receptor for PGE2 inhibits cAMP production and promotes platelet aggregation. Journal of Clinical Investigation 2001;107(5):603-610. [PubMed: 11238561]

26. Pavlovic S, et al. Targeting prostaglandin E2 receptors as an alternative strategy to block cyclooxygenase-2-dependent extracellular matrix-induced matrix metalloproteinase- 9 expression by macrophages. Journal of Biological Chemistry 2006;281(6):3321-3328. [PubMed: 16338931]

27. Maciejewski-Lenoir D, et al. Langerhans cells release prostaglandin D2 in response to nicotinic acid. Journal of Investigative Dermatology 2006;126(12):2637-2646. [PubMed: 17008871]

28. Schaloske RH, et al. Molecular characterization of the lipopolysaccharide/platelet activating factorand zymosan-induced pathways leading to prostaglandin production in P388D1 macrophages. Biochimica et Biophysica Acta 2005;1687(1-3):64-75. [PubMed: 15708354] 
29. Babaev VR, et al. Conditional Knockout of Macrophage PPAR [ $\{$ gamma $\}$ Increases Atherosclerosis in C57BL/6 and Low-Density Lipoprotein Receptor-Deficient Mice. Arterioscler Thromb Vasc Biol 2005;25(8):1647-1653. [PubMed: 15947238]

30. McAdam BF, et al. Systemic biosynthesis of prostacyclin by cyclooxygenase (COX)-2: The human pharmacology of a selective inhibitors of COX-2. Proc Natl Acad Sci USA 1999;96:272-277. [PubMed: 9874808]

31. Catella-Lawson F, et al. Effects of specific inhibition of cyclooxygenase-2 on sodium balance, hemodynamics, and vasoactive eicosanoids. Journal of Pharmacology \& Experimental Therapeutics 1999;289(2):735-741. [PubMed: 10215647]

32. Van Hecken A, et al. Comparative inhibitory activity of rofecoxib, meloxicam, diclofenac, ibuprofen, and naproxen on COX-2 versus COX-1 in healthy volunteers. Journal of Clinical Pharmacology 2000;40(10):1109-1120. [PubMed: 11028250]

33. Tuleja E, et al. Effects of cyclooxygenases inhibitors on vasoactive prostanoids and thrombin generation at the site of microvascular injury in healthy men. Arteriosclerosis, Thrombosis \& Vascular Biology 2003;23(6):1111-1115.

34. Hetu PO, Riendeau D. Cyclo-oxygenase-2 contributes to constitutive prostanoid production in rat kidney and brain. Biochemical Journal 2005;391(Pt 3):561-566. [PubMed: 16008526]

35. Kawka DW, et al. Double-label expression studies of prostacyclin synthase, thromboxane synthase and COX isoforms in normal aortic endothelium. Biochimica et Biophysica Acta 2007;1771(1):4554. [PubMed: 17189713]

36. Schonbeck U, et al. Augmented expression of cyclooxygenase-2 in human atherosclerotic lesions. American Journal of Pathology 1999;155(4):1281-1291. [PubMed: 10514410]

37. Baker CS, et al. Cyclooxygenase- 2 is widely expressed in atherosclerotic lesions affecting native and transplanted human coronary arteries and colocalizes with inducible nitric oxide synthase and nitrotyrosine particularly in macrophages. Arteriosclerosis, Thrombosis \& Vascular Biology 1999;19 (3):646-655.

38. Belton $\mathrm{O}$, et al. Cyclooxygenase-1 and -2-dependent prostacyclin formation in patients with atherosclerosis. Circulation 2000;102(8):840-845. [PubMed: 10952950]

39. Pratico D, et al. Acceleration of atherogenesis by COX-1-dependent prostanoid formation in low density lipoprotein receptor knockout mice. Proceedings of the National Academy of Sciences of the United States of America 2001;98(6):3358-3363. [PubMed: 11248083]

40. Burleigh ME, et al. Cyclooxygenase-2 promotes early atherosclerotic lesion formation in LDL receptor-deficient mice. Circulation 2002;105(15):1816-1823. [PubMed: 11956125]

41. Ueno N, et al. Coupling between cyclooxygenase, terminal prostanoid synthase, and phospholipase A2. Journal of Biological Chemistry 2001;276(37):34918-34927. [PubMed: 11418589]

42. Wong E, et al. Effects of COX-2 inhibitors on aortic prostacyclin production in cholesterol-fed rabbits. Atherosclerosis 2001;157(2):393-402. [PubMed: 11472739]

43. Topper JN, et al. Identification of vascular endothelial genes differentially responsive to fluid mechanical stimuli: cyclooxygenase-2, manganese superoxide dismutase, and endothelial cell nitric oxide synthase are selectively up-regulated by steady laminar shear stress. Proceedings of the National Academy of Sciences of the United States of America 1996;93(19):10417-10422. [PubMed: 8816815]

44. Inoue $\mathrm{H}$, et al. Transcriptional and posttranscriptional regulation of cyclooxygenase-2 expression by fluid shear stress in vascular endothelial cells. Arteriosclerosis, Thrombosis \& Vascular Biology 2002;22(9):1415-1420.

45. Voetsch B, et al. Nitric oxide insufficiency and atherothrombosis. Histochemistry \& Cell Biology 2004;122(4):353-367. [PubMed: 15338226]

46. Feletou M, Vanhoutte PM. Endothelial dysfunction: a multifaceted disorder (The Wiggers Award Lecture). American Journal of Physiology - Heart \& Circulatory Physiology 2006;291(3):H9851002. [PubMed: 16632549]

47. Verma S, et al. Cyclooxygenase-2 blockade does not impair endothelial vasodilator function in healthy volunteers: randomized evaluation of rofecoxib versus naproxen on endothelium-dependent vasodilatation. Circulation 2001;104(24):2879-2882. [PubMed: 11739299] 
48. Title LM, et al. Effect of cyclooxygenase-2 inhibition with rofecoxib on endothelial dysfunction and inflammatory markers in patients with coronary artery disease.[see comment]. Journal of the American College of Cardiology 2003;42(10):1747-1753. [PubMed: 14642682]

49. Bogaty $\mathrm{P}$, et al. Impact of prolonged cyclooxygenase-2 inhibition on inflammatory markers and endothelial function in patients with ischemic heart disease and raised C-reactive protein: a randomized placebo-controlled study. Circulation 2004;110(8):934-939. [PubMed: 15302800]

50. Monakier D, et al. Rofecoxib, a COX-2 inhibitor, lowers C-reactive protein and interleukin-6 levels in patients with acute coronary syndromes. Chest 2004;125(5):1610-1615. [PubMed: 15136366]

51. Tikiz C, et al. Selective COX-2 inhibition with different doses of rofecoxib does not impair endothelial function in patients with coronary artery disease. Acta Medica Okayama 2005;59(1):11-17. [PubMed: 15902994]

52. Chenevard R, et al. Selective COX-2 inhibition improves endothelial function in coronary artery disease.[see comment]. Circulation 2003;107(3):405-409. [PubMed: 12551863]

53. Widlansky ME, et al. Short- and long-term COX-2 inhibition reverses endothelial dysfunction in patients with hypertension. Hypertension 2003;42(3):310-315. [PubMed: 12874094]

54. McAdam BF, et al. Contribution of cyclooxygenase- 2 to elevated biosynthesis of thromboxane A2 and prostacyclin in cigarette smokers.[see comment]. Circulation 2005;112(7):1024-1029. [PubMed: 16087791]

55. Hermann M, et al. To the heart of the matter: coxibs, smoking, and cardiovascular risk.[comment]. Circulation 2005;112(7):941-945. [PubMed: 16103251]

56. Babaev VR, et al. Cyclooxygenase-1 deficiency in bone marrow cells increases early atherosclerosis in apolipoprotein E- and low-density lipoprotein receptor-null mice. Circulation 2006;113(1):108117. [PubMed: 16380543]

57. Group I-SISoISC. Randomised trial of intravenous streptokinase, oral aspirin, both, or neither among 17,187 cases of suspected acute myocardial infarction: ISIS-2. ISIS-2 (Second International Study of Infarct Survival) Collaborative Group. Lancet 1988;2(8607):349-360. [PubMed: 2899772]

58. Chen ZM, et al. Indications for early aspirin use in acute ischemic stroke : A combined analysis of 40000 randomized patients from the chinese acute stroke trial and the international stroke trial. On behalf of the CAST and IST collaborative groups. Stroke 2000;31(6):1240-1249. [PubMed: 10835439]

59. Collins R, et al. Antiplatelet therapy for thromboprophylaxis: the need for careful consideration of the evidence from randomised trials. Antiplatelet Trialists' Collaboration. Bmj 1994;309(6963): 1215-1217. [PubMed: 7987156]

60. Chesebro JH, et al. Antitrombotic therapy and progression of coronary artery disease: antiplatelet versus antitrombins. Circulation 1992;86:III-100-III-111. [PubMed: 1424043]

61. Ridker PM, et al. Low dose aspirin therapy for chronic stable angina. A randomized, placebocontrolled clinical trail. Ann Intern Med 1991;114:835-839. [PubMed: 2014943]

62. Ridker PM, et al. Inflammation, aspirin, and the risk of cardiovascular disease in apparently healthy men. N Engl J Med 1997;336:973-979. [PubMed: 9077376]

63. Mehta JL. Salutary effects of aspirin in coronary artery disease are not limited to its platelet inhibitory effects. Clinical Cardiology 1998;21(12):879-884. [PubMed: 9853178]

64. Bailey JM, Butler J. Anti-inflammatory drugs in experimental atherosclerosis. I. Relative potencies for inhibiting plaque formation. Atherosclerosis 1973;17(3):515-522. [PubMed: 4714810]

65. Egan KM, et al. Cyclooxygenases, thromboxane, and atherosclerosis: plaque destabilization by cyclooxygenase- 2 inhibition combined with thromboxane receptor antagonism. Circulation 2005;111(3):334-342. [PubMed: 15655126]

66. Ross R. The pathogenesis of atherosclerosis - a perspective for the 1990's. Nature 1993;362:801809. [PubMed: 8479518]

67. Olesen M, et al. No effect of cyclooxygenase inhibition on plaque size in atherosclerosis-prone mice. Scandinavian Cardiovascular Journal 2002;36(6):362-367. [PubMed: 12626204]

68. Rott D, et al. Effects of MF-tricyclic, a selective cyclooxygenase-2 inhibitor, on atherosclerosis progression and susceptibility to cytomegalovirus replication in apolipoprotein-E knockout mice. Journal of the American College of Cardiology 2003;41(10):1812-1819. [PubMed: 12767669] [comment] 
69. Bea F, et al. Chronic inhibition of cyclooxygenase- 2 does not alter plaque composition in a mouse model of advanced unstable atherosclerosis. Cardiovascular Research 2003;60(1):198-204. [PubMed: 14522423]

70. Linton MF, Fazio S. Cyclooxygenase-2 and inflammation in atherosclerosis. Current Opinion in Pharmacology 2004;4(2):116-123. [PubMed: 15063354]

71. Burleigh ME, et al. Cyclooxygenase-2 promotes early atherosclerotic lesion formation in ApoEdeficient and C57BL/6 mice. Journal of Molecular \& Cellular Cardiology 2005;39(3):443-452. [PubMed: 16040051]

72. Jacob S, et al. The Select Cyclooxygenase-2 Inhibitor Celecoxib Reduced the Extent of Atherosclerosis in Apo E-/- Mice. J Surg Res. 2007in press. Available online 22 October 2007

73. Metzner J, et al. The effects of COX-2 selective and non-selective NSAIDs on the initiation and progression of atherosclerosis in ApoE-/- mice. Journal of Molecular Medicine 2007;85(6):623633. [PubMed: 17318614]

74. Reddick RL, et al. Atherosclerosis in mice lacking apo E. Evaluation of lesional development and progression [published erratum appears in Arterioscler Thromb 1994 May;14(5):839]. Arterioscler Thromb 1994;14(1):141-147. [PubMed: 8274470]

75. Nakashima Y, et al. ApoE-deficient mice develop lesions of all phases of atherosclerosis throughout the arterial tree. Arterioscler Thromb 1994;14:133-140. [PubMed: 8274468]

76. Belton OA, et al. Cyclooxygenase isoforms and platelet vessel wall interactions in the apolipoprotein E knockout mouse model of atherosclerosis. Circulation 2003;108(24):3017-3023. [PubMed: 14638539]

77. Eligini S, et al. Oxidized low density lipoprotein suppresses expression of inducible cyclooxygenase in human macrophages. Arteriosclerosis, Thrombosis \& Vascular Biology 1999;19(7):1719-1725.

78. Joseph SB, et al. Reciprocal regulation of inflammation and lipid metabolism by liver $\mathrm{X}$ receptors. Nature Medicine 2003;9(2):213-219.

79. Kothapalli D, et al. Antimitogenic effects of HDL and APOE mediated by Cox-2-dependent IP activation. Journal of Clinical Investigation 2004;113(4):609-618. [PubMed: 14966570]

80. Linton MF, et al. Prevention of atherosclerosis in apoE deficient mice by bone marrow transplantation. Science 1995;267:1034-1037. [PubMed: 7863332]

81. Babaev VR, et al. Macrophage lipoprotein lipase promotes foam cell formation and atherosclerosis in vivo. J Clin Invest 1999;103:1697-1705. [PubMed: 10377176]

82. Makowski L, et al. Lack of macrophage fatty-acid-binding protein aP2 protects mice deficient in apolipoprotein E against atherosclerosis. Nature Medicine 2001;7:699-705.

83. Vane JR, et al. Cyclooxygenase 1 and 2. Ann Rev Phamacol Toxicol 1998;38:97-120.

84. Needleman P, Isakson PC. The discovery and function of COX-2. J Rheumatol 1997;24:6-8. [PubMed: 9002003]

85. Masferrer JL, et al. Selective regulation of cellular cyclooxygenase by dexamethasone and endotoxin in mice. J Clin Invest 1990;86:1375-1379. [PubMed: 2120289]

86. Michelsen KS, et al. Lack of Toll-like receptor 4 or myeloid differentiation factor 88 reduces atherosclerosis and alters plaque phenotype in mice deficient in apolipoprotein E. Proceedings of the National Academy of Sciences of the United States of America 2004;101(29):10679-10684. [PubMed: 15249654]

87. Peters W, Charo IF. Involvement of chemokine receptor 2 and its ligand, monocyte chemoattractant protein-1, in the development of atherosclerosis: lessons from knockout mice. Current Opinion in Lipidology 2001;12(2):175-180. [PubMed: 11264989]

88. Hinson RM, et al. Elevated interleukin 6 is induced by prostaglandin E2 in a murine model of inflammation: possible role of cyclooxygenase-2. Proceedings of the National Academy of Sciences of the United States of America 1996;93(10):4885-4890. [PubMed: 8643498]

89. Kim CJ, et al. Polymerase chain reaction-based method for quantifying recruitment of monocytes to mouse atherosclerotic lesions in vivo: enhancement by tumor necrosis factor-alpha and interleukin-1 beta. Arteriosclerosis, Thrombosis \& Vascular Biology 1976;20(8):1976-1982.

90. Litovsky S, et al. Superparamagnetic iron oxide-based method for quantifying recruitment of monocytes to mouse atherosclerotic lesions in vivo: enhancement by tissue necrosis factor-alpha, 
interleukin-1beta, and interferon-gamma. Circulation 1545;107(11):1545-1549. [PubMed: 12654614]

91. Blessing $\mathrm{E}$, et al. Lesion progression and plaque composition are not altered in older apoE-/- mice lacking tumor necrosis factor-alpha receptor p55. Atherosclerosis 2004;176(2):227-232. [PubMed: 15380444]

92. Schreyer SA, et al. Loss of lymphotoxin-alpha but not tumor necrosis factor-alpha reduces atherosclerosis in mice. Journal of Biological Chemistry 1236;277(14):12364-12368. [PubMed: 11809756]

93. Hirsch AT, et al. ACC/AHA 2005 Practice Guidelines for the management of patients with peripheral arterial disease (lower extremity, renal, mesenteric, and abdominal aortic): a collaborative report from the American Association for Vascular Surgery/Society for Vascular Surgery, Society for Cardiovascular Angiography and Interventions, Society for Vascular Medicine and Biology, Society of Interventional Radiology, and the ACC/AHA Task Force on Practice Guidelines (Writing Committee to Develop Guidelines for the Management of Patients With Peripheral Arterial Disease): endorsed by the American Association of Cardiovascular and Pulmonary Rehabilitation; National Heart, Lung, and Blood Institute; Society for Vascular Nursing; TransAtlantic Inter-Society Consensus; and Vascular Disease Foundation. Circulation 2006;113(11):e463-654. [PubMed: 16549646]

94. Daugherty A, et al. Angiotensin II promotes atherosclerotic lesions and aneurysms in apolipoprotein E-deficient mice.[see comment]. Journal of Clinical Investigation 2000;105(11):1605-1612. [PubMed: 10841519]

95. King VL, et al. Selective cyclooxygenase-2 inhibition with celecoxib decreases angiotensin II-induced abdominal aortic aneurysm formation in mice.[see comment]. Arteriosclerosis, Thrombosis \& Vascular Biology 2006;26(5):1137-1143.

96. Gitlin JM, et al. Genetic deficiency of cyclooxygenase-2 attenuates abdominal aortic aneurysm formation in mice. Cardiovascular Research 2007;73(1):227-236. [PubMed: 17137566]

97. Cheng Y, et al. Role of prostacyclin in the cardiovascular response to thromboxane A2. Science 2002;296(5567):539-541. [PubMed: 11964481]

98. Kobayashi T, et al. Roles of thromboxane A(2) and prostacyclin in the development of atherosclerosis in apoE-deficient mice. Journal of Clinical Investigation 2004;114(6):784-794. [PubMed: 15372102]

99. Egan KM, et al. COX-2-derived prostacyclin confers atheroprotection on female mice. Science 2004;306(5703):1954-1957. [PubMed: 15550624]

100. Cheng Y, et al. Cyclooxygenases, microsomal prostaglandin E synthase-1, and cardiovascular function. Journal of Clinical Investigation 2006;116(5):1391-1399. [PubMed: 16614756]

101. Cayatte AJ, et al. The thromboxane receptor antagonist S18886 but not aspirin inhibits atherogenesis in apo E-deficient mice: evidence that eicosanoids other than thromboxane contribute to atherosclerosis. Arteriosclerosis, Thrombosis \& Vascular Biology 2000;20(7):1724-1728.

102. Zhuge $\mathrm{X}$, et al. Protection of atherogenesis in thromboxane A2 receptor-deficient mice is not associated with thromboxane A2 receptor in bone marrow-derived cells. Biochemical \& Biophysical Research Communications 2006;351(4):865-871. [PubMed: 17097058]

103. Sampey AV, et al. Microsomal prostaglandin E synthase-1: the inducible synthase for prostaglandin E2. Arthritis Research \& Therapy 2005;7(3):114-117. [PubMed: 15899061]

104. Wang M, et al. Deletion of microsomal prostaglandin E synthase-1 augments prostacyclin and retards atherogenesis. Proceedings of the National Academy of Sciences of the United States of America 2006;103(39):14507-14512. [PubMed: 16973753]

105. Cipollone F, et al. Overexpression of functionally coupled cyclooxygenase-2 and prostaglandin E synthase in symptomatic atherosclerotic plaques as a basis of prostaglandin $\mathrm{E}(2)$-dependent plaque instability. Circulation 2001;104(8):921-927. [PubMed: 11514380]

106. Cipollone F, et al. Suppression of the functionally coupled cyclooxygenase-2/prostaglandin E synthase as a basis of simvastatin-dependent plaque stabilization in humans. Circulation 2003;107 (11):1479-1485. [PubMed: 12654603] 
107. Cipollone F, et al. Blockade of the angiotensin II type 1 receptor stabilizes atherosclerotic plaques in humans by inhibiting prostaglandin E2-dependent matrix metalloproteinase activity. Circulation 2004;109(12):1482-1488. [PubMed: 15037537]

108. Cipollone F, et al. Balance between PGD synthase and PGE synthase is a major determinant of atherosclerotic plaque instability in humans. Arteriosclerosis, Thrombosis \& Vascular Biology 2004;24(7):1259-1265.

109. Cipollone F, et al. Association between prostaglandin E receptor subtype EP4 overexpression and unstable phenotype in atherosclerotic plaques in human. Arterioscler Thromb Vasc Biol 2005;25 (9):1925-1931. [PubMed: 16020747]

110. Cipollone F, et al. A polymorphism in the cyclooxygenase 2 gene as an inherited protective factor against myocardial infarction and stroke. Jama 2004;291(18):2221-2228. [PubMed: 15138244]

111. Hata AN, Breyer RM. Pharmacology and signaling of prostaglandin receptors: multiple roles in inflammation and immune modulation. Pharmacol Ther 2004;103(2):147-166. [PubMed: 15369681] 

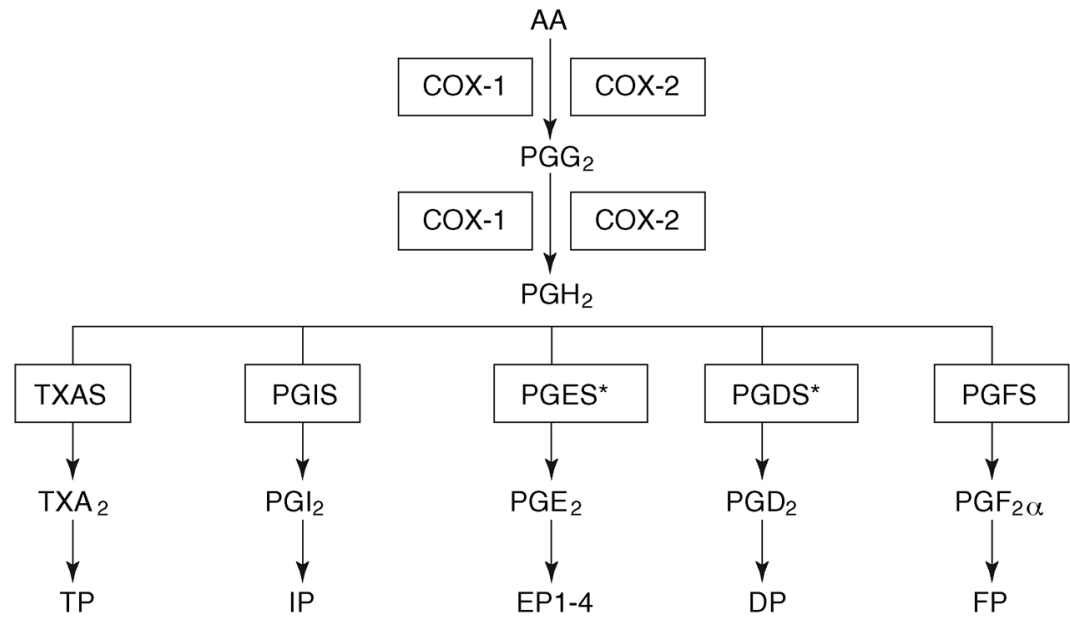

Figure 1.

Arachidonic acid (AA) is first oxidized by cyclooxygenase (COX)-1 or COX-2 to PGG2, which is then peroxidized to $\mathrm{PGH} 2$, an unstable endoperoxide that serves as the common precursor for the 5 principle prostaglandins. Synthesis of Thromboxane(TX) A2, PGI2, PGE2, PGD2, and PGF2a is mediated by specific synthases (TXAS, PGIS, PGES, PGDS, and PGFS). * Three synthases have been identified for PGE2: cPGES, mPGES-1, and mPGES-2; two synthases generate PGD2. Prostaglandins mediate their biological effects by activating the indicated cell surface G-protein-coupled receptors[111]. 


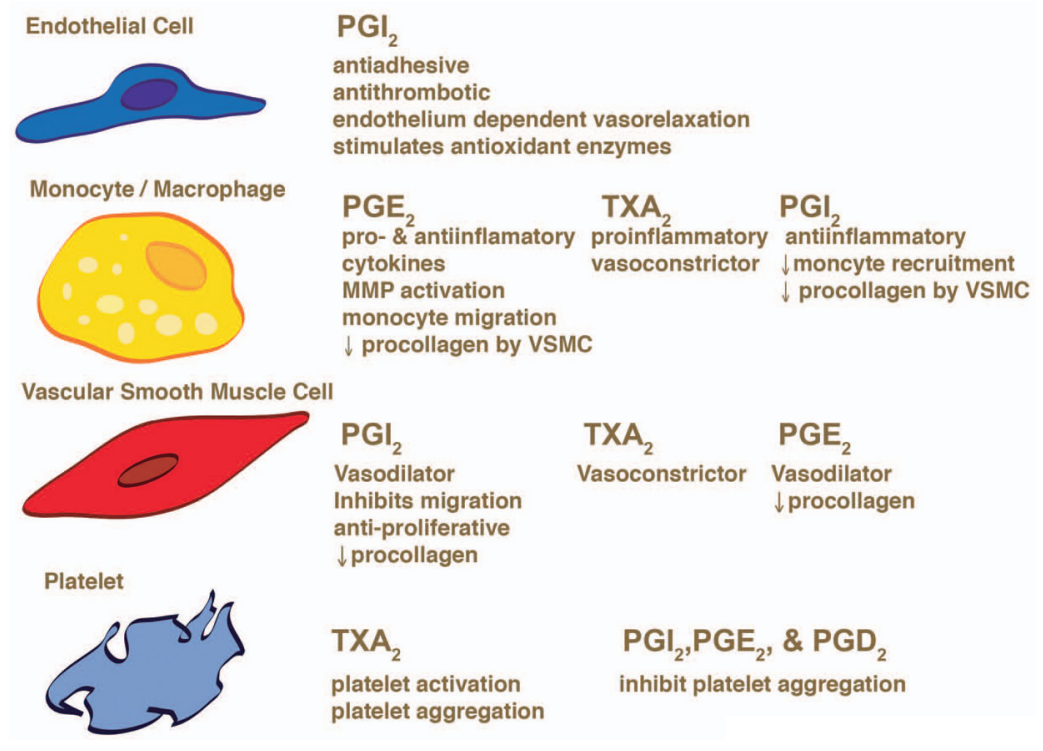

Figure 2.

Proposed roles for prostaglandins in atherothrombosis according to cell type. 